\title{
RESTORATION TECHNIQUES FOR THE HERITAGE BUILDING / KIRKUK QISHLA AS A CASE STUDY
}

\author{
Sumbul Muhammed YUNUS* \\ College of Engineering, Kirkuk University, Kirkuk, Iraq \\ Received 18 September 2018; accepted 12 November 2019
}

\begin{abstract}
National heritage buildings are considered as the memory of the cities and its civilization's legacy. Such buildings are receiving more attention these days especially from architectures who are trying to restore them by using the proper techniques to bring them back to their former appearance to serve the community in the present time.

From that point, the general goal of this research is to concentrate on the used techniques of restoring national heritage buildings by using the proper materials for the damaged or the collapsed parts as the restoration process differs from a building to another. All these points should be done according to the laws and protocols of UNSCO and ICOMOS to keep the authentic features of the building and pass it on to the next generations.

This research deals specifically and practically with restoring the Qishla building in Kirkuk as a restoration sample. Some parts of that building collapsed recently and the research aims to save that building by studying the techniques of restoring it using the materials and building techniques of the era the building was built in.

This research rises an important point, which is finding a general prospective of scientific and technical ways in restoring cultural heritage buildings which are made from stone specifically.

From all that above the main issue that this research deals with is "The unclear techniques of restoring cultural heritage buildings in general and the restoration process of Qishla building with stone in specific".

Accomplishing the aim of this research lies in two points:

First: Studying the rules which govern the restoration process of cultural heritage buildings.

Second: Studying the restoration process of Qishla building and that includes; the restoration process with stone should be done by examining the chemical and physical features of the stone, durability of the used stone, conducting chemical tests in international labs as (ACMAE ANALYSES/ Canada) and the last step is to analyze and discuss the results to take final decisions.
\end{abstract}

Keywords: Restoration technique, Qishla of Kirkuk, restoration with stone, chemical test of stone, physical test of stone.

\section{Introduction}

The restoration concept of the architectural civilization heritage is one of the important concepts which started to emerge in the architectural theses which are concerned of cultural heritage buildings. The restoration process is based, totally, on a group of regulations and rules set by UNSCO and ICOMOS and the restoration process differs from a country to another according to the privacy of the cultural heritage building which is intended to be restored (Feilden, 2003).

The Iraqi law of Antiques Protection Act 22 of 2002 states that; the authentic appearance of the historical heritage should be protected and the used restoration materials should be identical to the original materials (Republic of Iraq, 2002).
This research concentrated on restoring the walls of the Qishla of Kirkuk because that building is one of significant heritage buildings which located in Kirkuk city north of Iraq in Asia. This building was established to be the headquarters of the Ottoman army. Some of the walls of that building, which has been built with stones, collapsed recently.

In order to find similar materials to the original used stone in building the Qishla, two types of stones has been selected; the first one is from Laylan quarry and the second one is from Debis quarry. The strength of the chosen stones is taken into consideration depending on compression test to choose the stronger type and water absorbance test to choose the type with less absorbance.

*Corresponding author. E-mail: mimarsumbul@yahoo.com 


\section{Objectives}

The main objective of carrying out the study was firstly, to seek for restoration materials which have the same structural properties as the original ones so that they provide good functionality in the old buildings, making the buildings more durable with minimum intervention. Secondly, by matching the original materials techniques closely, the repair materials would age in a similar manner as the original materials. The significance of this study has been to ensure that, these historic buildings continue to exist.

\section{The concept of restoration}

The restoration means repairing things that are damaged because the thing which is being repaired is valuable, beneficial, and beautiful or has a cultural value for humans (Feilden, 2003).

The term "Restoration" also refers to the work done by restorers who work on archeological buildings (Republic of Iraq, 2002).

The objective of restoration is to revive the original concept or legibility of the object. Restoration and reintegration of details and features occur frequently and is based upon respect for original materials, archeological evidences, original design and authentic documents. Replacement of missing and decayed parts must integrate harmoniously with the whole, but must be distinguishable on close inspection from the original so that the restoration does not falsify the artistic or historic evidence (Feilden, 2003).

It is obvious from the definitions above that restoration means rebuilding the worn parts of a historical building to bring back to its original condition as it was before.

\subsection{Types of restoration techniques in heritage buildings}

- Restoration with total reconstruction technology: Includes heritage buildings that have been collapsed or destroyed in whole or in large part for various reasons, total reconstruction can also be used in case of relocation historical buildings when exposed to high risk or because of the necessity of construction.

- Restoration with partial reconstruction technology: Include historic buildings that have been partially collapsed, as a result of the building being exposed to various damage factors that may lead to the collapse or destruction of some parts of these historic buildings. This is the focus of the research later (Bassam, 2008).

\subsection{Requirements for repair materials in Partial reconstruction}

Restoration is the action to prevent decay. This problem is multi-disciplinary and evolve many skills which contribute to the solution (Lakhani \& Sharma, 2018). The first step is document the history of the building. The second step is to document the architectural elements of the building.
The third step is the construction documents. This step includes a series of studies and tests to examine the building structurally and take appropriate procedures for the restoration of the historic building, including: Completing the missing parts through the selection of appropriate materials for the restoration of the building (ICOMOS, 2003). By conducting chemical and physical tests of the selected materials, reaching the structural material closest to the original material and characterized by durability.

Selection of materials to be employed in the restoration work requires some understanding of the chemical and physical properties of these materials, as well as their long term behavior under the conditions prevailing their on the outdoor weathering. The two main properties of repair materials, which satisfy the durability requirements are: compatibility with the material being repaired and adhesion guaranteeing durable jointing effect. Compatibility of materials means that their mechanical, physical, rheological and chemical features correspond to or similar to each other. The restored fragment should not be "an align body" (Lakhani \& Sharma, 2018).

Thus, the research focuses on finding the building materials for the historical building of Kirkuk Qishla after the collapse of parts of it in order to preserve and reduce the process of collapse.

\section{Laws and international charters which are related the restoration of heritage buildings}

Different internationals laws and charters assured on the importance of preserving and maintaining cultural heritage buildings by restoration operations and rebuilding and operations can be done by using different restoration techniques according to the laws of concerned country (Feilden, 2003).

Many buildings in Iraq had been restored like the Qishal of Baghdad, some old heritage cultural houses and the Citadel of Irbil. All these given examples were restored by using similar materials to the original used materials as the Iraqi law of Antiques Protection Act 22 of 2002 stated, to preserve the antiquity and the historical appearance of these buildings (Republic of Iraq, 2002).

It is obvious from all the above mentioned information that the restoration operations are subject to different policies and techniques according to the restoration plan of each country and the way they want to keep their national heritage whether their policies is to keep the original design of the building or by using different materials and designs in restoration process.

\subsection{The main rules and legislation governing the partial reconstruction of historic buildings}

Because of the importance of restoration of historical buildings that have collapsed or destroyed parts of it, it is necessary that these operations are based on rules and determinants approved by many scientific conferences and international conventions on dealing with historic 
buildings, the most important of which are (Aldhdar, 2010).

- Based on a proven scientific and historical support in the process of restoration and reconstruction, in order to maintain and preserve the impact of the deterioration.

- Parts that are rebuilt or completed in harmony with the historical building shall be integrated and distinct in appearance from the original.

- Complete the missing parts of the historic building using original materials, In the absence of original materials, an alternative should be found that is as close to the specifications of the original material as possible and of high durability.

- Use technological development to find suitable alternatives to the collapsed parts of the historic building in order to maintain and sustain (ICOMOS, 2003).

\subsection{Restoration techniques for partial reconstruction of stone buildings "Church of Our Lady in Breda"}

The Grote Kerk or Onze-Lieve-Vrouwekerk (Church of Our Lady) (Figure 1) is the most important monument and a landmark of Breda. The church is built in the Brabantine Gothic style. The tower of the church is 97 meters tall. The plan is in the shape of a Latin Cross (see Figure 2).

The oldest parts of the Church of Our Lady in Breda date back to the 15th century. The current state of the building is the result of two large conservation campaigns in the 20th century.

The restoration process in the church was related to the replacement of the dilapidated parts of the original stone with a new one based on the principle of compatibility established by the Charters of Conservation in the process of replacement (Quist, 2009).
The conservation status of natural stones was assessed at the Church of Our Lady. Based on optical and electron microscopy (see Figure 2), the situation is alarming: due to the structural damages, the severely decayed stone can easily collapse. The most compromised pieces should be substituted (Quist, 2009).

Term compatibility was introduced at the Dahlem conference (Teutonico et al., 1997). Compatibility means that treatments or introduced materials will not have negative consequences for the existing historic fabric, neither in a technical, esthetical nor historical way. Those three aspects of compatibility can be subdivided into several dimensions to cover all the characteristics of the intervention. For each dimension it is necessary to establish acceptable compatibility tolerance limits to asses and compare interventions. Reasoned replacement of natural stone in historic buildings has been common practice in conservation campaigns over the years (Quist, 2009).

A treated material should have mechanical, physical and chemical compatibility with the untreated historic materials under consideration. Simply stated, compatibility means that introduced treatment materials will not have negative consequences and other values like colour, texture, and aesthetic presentation must be considered

Many (decorative or structural) elements have been replaced and mortar repair or replacement of blocks of natural stone. Due to evolution of conservation philosophy, legislation, the availability of new investigation techniques, better knowledge of material properties, and a broader offer and availability of alternative stone types, conservation practice has changed slowly over the years.

After research and testing to find the replacement stone, it was decided to replace the original Balinese stone with Portland limestone and tracheal type for compatibility with the original stone characteristics to ensure the preservation of the historic building (Quist, 2009).

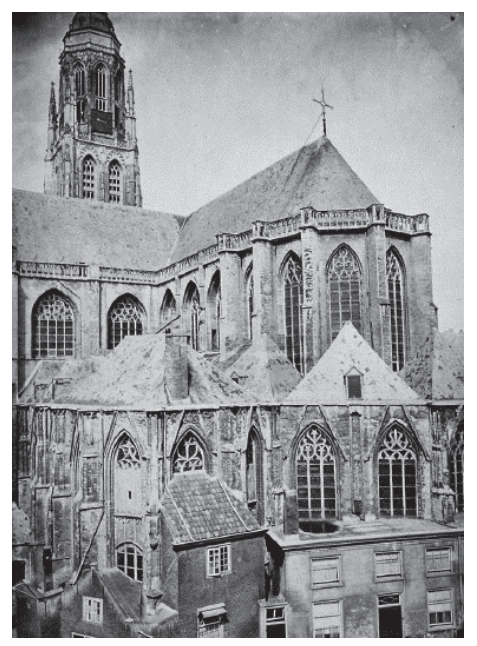

Figure 1. Church of Our Lady (Quist, 2009)
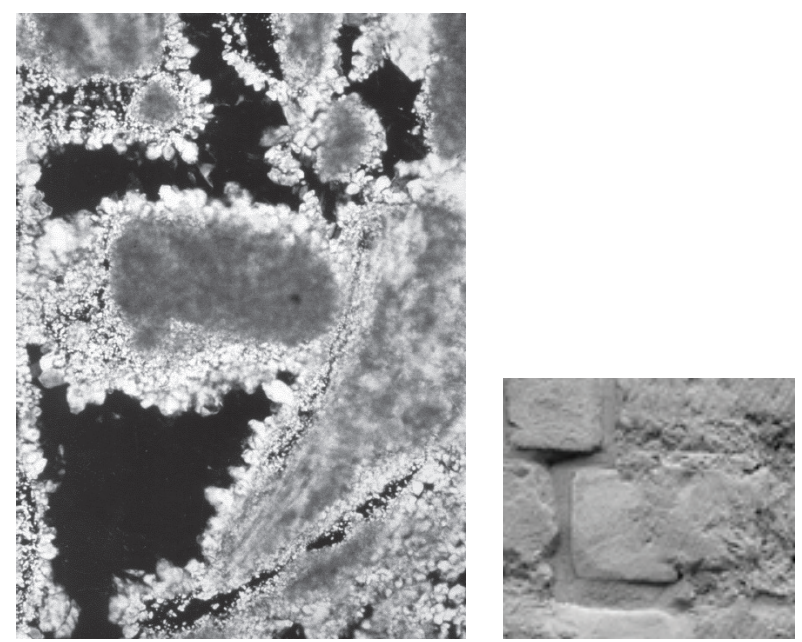

Figure 2. PFM-micro photo of a sample of olitic lime stone, size of the micrograph is $1.4 \times 0.9 \mathrm{~mm}$ (Quist, 2009) 


\section{The specifications of the stone tests}

First: The chemical specifications of stones: This test depends on XRF machine which tests the components of the stone after grinding it.

Two: The physical specifications of stones: This test depends on the Iraqi-American code ASTM to extract the specification of the stones. This test includes the following steps:

- Total absorbance test: this test determines the total water absorbance with qualitative weight and absorbance, according to the American code ASTM-C119. The best stone is the one with less water absorbance. The water absorbance increase if the stone is more porous or has more clay minerals in it.

- Compression resistance test: This test is designed to measure the pivot compression resistance of the stone.

- Specific gravity test: There is a relation between absorbance and specific gravity, there is an inversely proportion between the two.

(a) Structural restoration of stone:

Building by stones is one of the oldest construction methods in history, due to its availability from mountains and quarries it is widely spread built method and because it makes most of the old buildings characterized by strength, durability and beauty at the same time (Iraq, specification, 1984).

(b) Classification of structural rocks:

Sedimentary rocks: formed from the hardening of sediment, which resulted from the fragmentation of rocks by erosion factors after being transported to the place of deposition by water or air. Its characterized by its applicable and amorphous formation which is less harsh and homogeneous, with various physical properties. The most important types of these rocks are limestone rocks and sand rocks (Mibei, 2014).

(c) Basic considerations in the selection of constructing stone:

- All stones imported to the site should be from one quarry and one layer and should be supplied in one shipment. Stones should be free of gaps, cracks, stains, parasitic veins and any other materials that may affect the strength, bearing or appearance of the stones (Saudi commission for tourism \& antiquities, 2009).

- The length of the stone exposed to pressure in the buildings should not be more than three times the width of the stone and the height of the stone is $1-1.5$ of its width, the direction of pressure bearing in the bearing wall is vertical, the stresses at the bottom of the strip do not exceed $50-60 \mathrm{~kg} / \mathrm{cm}$.

- The sectioned stones should be from the deep layers of the quarries, and the quarrying should not be superficial and directly exposed to factors of carving, erosion and corrosion with laboratory test to determine the mechanical properties (the allowable stress of the construction subsistence in every project) (Charola, 2016).

(d) The most important problems of stone construction and its solution:

The traditional stone buildings are faced by many problems through the time, some of them by nature such as saults, this can be fixed by removing a layer of salt on the surface of the stone by washing and spraying with water, removing the fungus layer, algae and harmful grass on the face of the stone with special non-harmful substances such as fungi. The industrial problem facing the stone is caused by faulty repair treatments, such as the use of cement in external finishing's, which is treated by removing and cleaning the cement layer, removing the layers of oil and paints with special materials, treating the stones exposed to burn through the use of sand pumps and sometimes water spray pumps (Paajanen \& Muinonen, 2013) see Figure 3.

\section{Specifications for the selection of stone}

First: Chemical Specification of Limestone: Includes quarantine test by a testing device of stone compounds after grinding.

Second: Physical specifications of the stone: according to the Iraqi code and the American code ASTM CODE (C170c170M-15a).

1. The total absorbance test: This experiment is conducted to determine the percentage of water absorption of the stone through the specific weight and absorption. According to ASTM-C119, the best stone is the less absorbent stone. The absorption ratio increases due to increased porosity of the stone.

2. Compression resistance test: We conduct this test to find the amount of tolerance of stone by measuring the ability to resist the forces of central pressure.

3. Specific density test: used to set the specific density of the stone (Strenchock, 1999), there is a close correlation between the density of the stone and the absorption rate, as absorption is proportional to the density. This means that the differences observed in the absorption will be
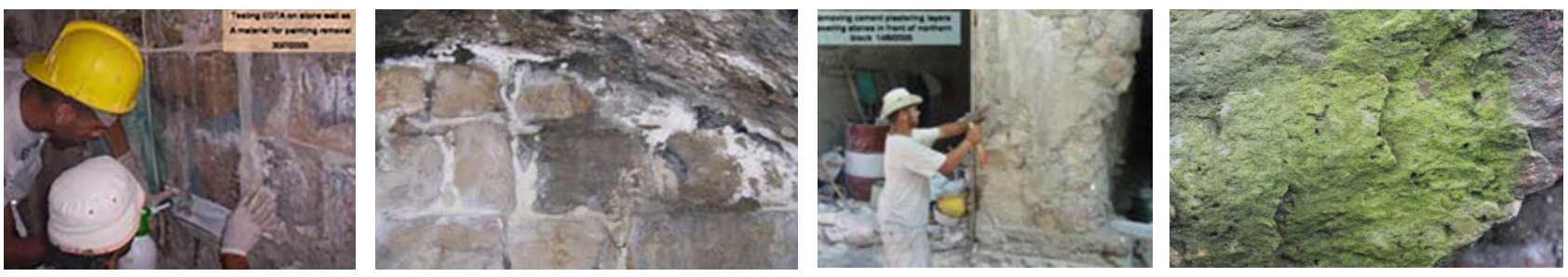

Figure 3. The problems of stone construction (Paajanen \& Muinonen, 2013) 
observed in the density, as the American specifications ASTMC97 set the density between (2.16-2.7) (Iraq, specification, 1984).

\section{Study sample (The Qishla of Kirkuk)}

The word "Qishla" is taken from the word "Qishlagh" which means winter shelter or the place where the soldiers stay in winter to protect them from weather elements. The Qishla was designed to be barracks for the soldiers during peace time (Saatci, 2014), see Figure 4a, 4b.

\subsection{General description of Qashla Building in Kirkuk}

The Qishla is one of the old buildings in Kirkuk. It was a headquarter of the Ottoman Army in Iraq, the building was established in 1863 in the era of Sultan Abdul Azez Khan. The building covers 24282 square meters. The building was handed to the Department of Culture and Archaeology which was a part of the Ministry of Culture and Media in 1971 (Saatci, 2014). Qishla is consisted of two floors with a big internal yard, the rooms are distributed around the yard as a $\mathrm{U}$ shape. A corridor with arches separates between the rooms and the yard. The arches are based on columns which have a square base of $70 \mathrm{~cm}$ then the columns has a cylinder shape. The rooms are supported by big slopped columns built from stones. The building has four gates; a main gate from the south overlooks on the main street and the other two gates are from west (Terzibasi, 1988). The Qishla had been restored in 1967, the northern wing of the building and half of the western side was demolished and the other parts were preserved from inside and outside (Saatci, 2014).

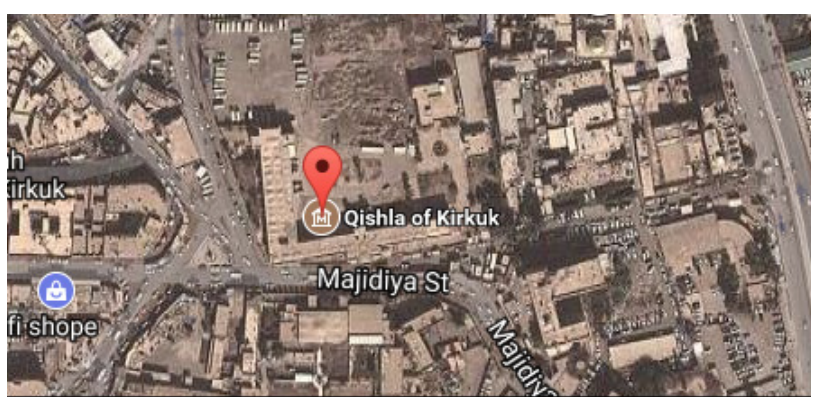

a)

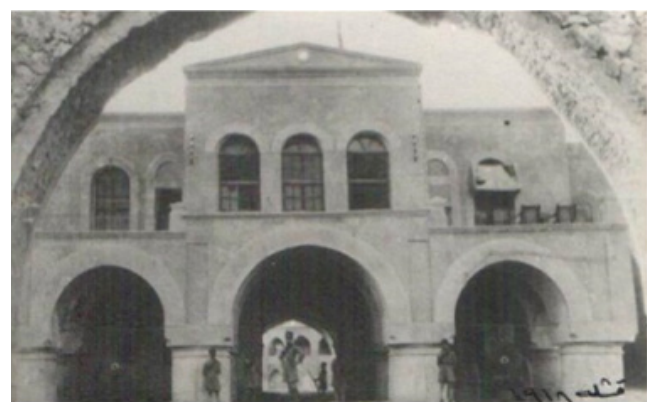

b)

Figure 4. a) Shows the horizontal map for Kirkuk's Qishla; b) - Qishla in 1918
The building was restored from inside and outside in 2006. After that the building suffered from reflectance until the present day. There are serious cracks in the building and the western side of the building collapsed. All these reasons put that building in need of restoration and to rebuild the western collapsed side (Mardan, 2015).

\subsection{The structure of Qishla and used materials}

The structure of the building depends on the walls which carry the weight of the arches and the domes on the foundation which is made from stones. The main used material of the walls, supporting columns of the walls and the foundation is stone. The used binder is plaster. The used material of the ceiling is mud and wooden bridges to support it. The internal and the external finishing of the building are made from plaster (Terzibasi, 1988) see Figure 5.

\section{Test methods}

Laboratory tests to select the appropriate sample for restoration: The Laboratory tests include two main stages:

- Chemical test of selected samples.

- Physical test of selected samples.

(a) Phase I: Chemical test of the selected samples:

Chemical analysis includes the percentage of each of the chemical compounds of the stone in specialized laboratories and equipment such as FXR, through the chemical test of the compounds of the original material of the building (original Qishla stone), and compare them with the results of the chemical examination of the selected sample compounds (Dibis Quarry stone) (Leylan Quarry stone), And the selection of the closest sample in the structural properties of the original building material (the original stone of the Qishla), As shown in the default form (3-9) where sample B is the closest in its chemical properties to the original sample see Figure 6 .

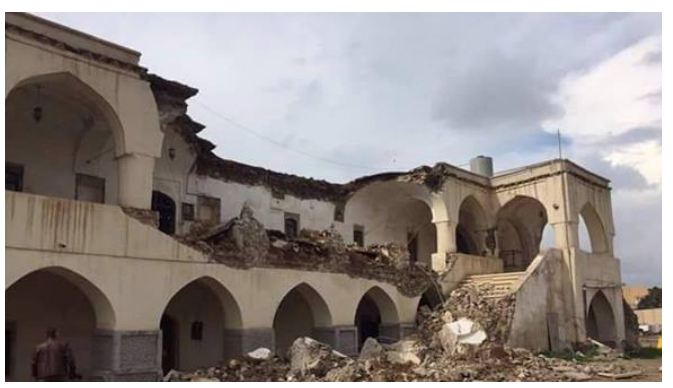

Figure 5. The collapsing part of the inside of Qishla (researcher)

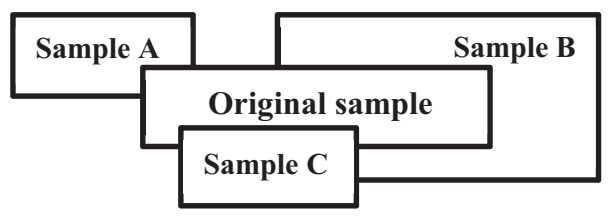

Figure 6. A default model for the method of selection of the sample closest to its chemical properties of the original material (researcher) 
(b) Stage 2: Physical test of the selected samples: Includes

- test of compressibility and absorption rate of stone according to American specifications (ASTM).

- test of compression of plaster mortar according to Iraqi specifications (IQS).

1-Compression test of the stone

The purpose of the test is to find the amount of stone bearing pressure, standard number: (ASTM C170c170M15a).

1. Sensitive electronic balance $0.1 \mathrm{~g}$ to measure the weight of the samples.

2. Ruler for measuring dimensions.

3. The compression test device loads the load on the sample until the failure occurs and then calculates the stress.

4. Special device to cut the models and convert them into regular forms, a special device for cutting the stones with a water cooling system to reduce the heat resulting from the cutting process and the device supports four supports from the bottom.

5. A basin in which water is placed for modelling in which form.

6. Heat oven with thermal capacity $\left(110^{\circ}\right)$ to dry the models and get rid of the moisture in it forms.

\section{Physical measurement method}

(a) Test the compression of the stone:

1. The samples of the test were prepared by three models for each sample in order to achieve both average stress and average water absorption ratio for each sample. Three models (a1, a2, a3) for the original sample (Qishlas stone) (A), three models (al1, al2, al3) of Leylan stone (AL), three models (ad1, ad2, ad3) of Dibis stone (AD). Were collected by cutting them and turning them and to regular cubes with dimensions $(5 \times 5 \times 5 \mathrm{~cm})$ using cutting device.

2. Samples were placed in the water tank for 48 hours at of $\left(22 \pm 2{ }^{\circ} \mathrm{C}\right)$ temperature to test the samples in the weakest cases.

3. Extract the sample models from the basin after 48 hours and dry them with a piece of cloth and then place the samples in compression device directly.
4. The models were tested by applying a load with loading rate of $(690 \mathrm{kPa} /$ second $)$. The failure load is recorded and the stress was found as shown in see Figure 7.

5. The pressure was calculated using the following equation:

Stress $\left(\mathrm{KN} / \mathrm{mm}^{2}\right)=$ Pressure load at failure $(\mathrm{kN}) /$ area $\left(\mathrm{mm}^{2}\right)$

(b) Absorption of the stone

(1) - The purpose of the test is to find the percentage of stone absorption of water (ASTM C170c170M-15a)

(2) Tools and devices:

1. Sensitive electronic balance up to $0.1 \mathrm{~g}$ to measure the weight of the samples.

2. A basin with water to put samples in.

3. Heat oven with heat capacity $\left(110^{\circ} \mathrm{C}\right)$ to dry the samples as in (15D).

(c) Method:

1. The sample was placed in the water basin for 48 hours.

2. After 48 hours, sample models were extracted from the basin, and the weight was measured and the symbol (C) is used for the (wet weight).

3. Put the models in the electric oven and we wait for stability of Models Weight, use the symbol (D) for the dry weight.

4. Calculate the stone absorption ratio for each model and using the following equation

List of abbreviations:

C: wet weight of sample models

D: dry weight of sample models

Accounts:

Absorption ratio $=(\mathrm{C}-\mathrm{D}) / \mathrm{D}^{*} 100(2)$

(d) Compression test of plaster mortar:

- The purpose of the test is to find the amount of tolerance plaster to pressure, Standard No. (IQS 27-1985).

- Tools and devices:

1. Cubes with dimensions of $(5 \times 5 \times 5) \mathrm{cm}$, the maximum permissible deviation of the interior faces 0.005 $\mathrm{cm}$ were the angle between the inner faces should be 90 degrees and the maximum permissible deviation is $\pm 0.5^{\circ}$ measured at points adjacent to the intersection line.

2. The compression test device loads the applied on the sample until the failure occurs and calculates the stress.
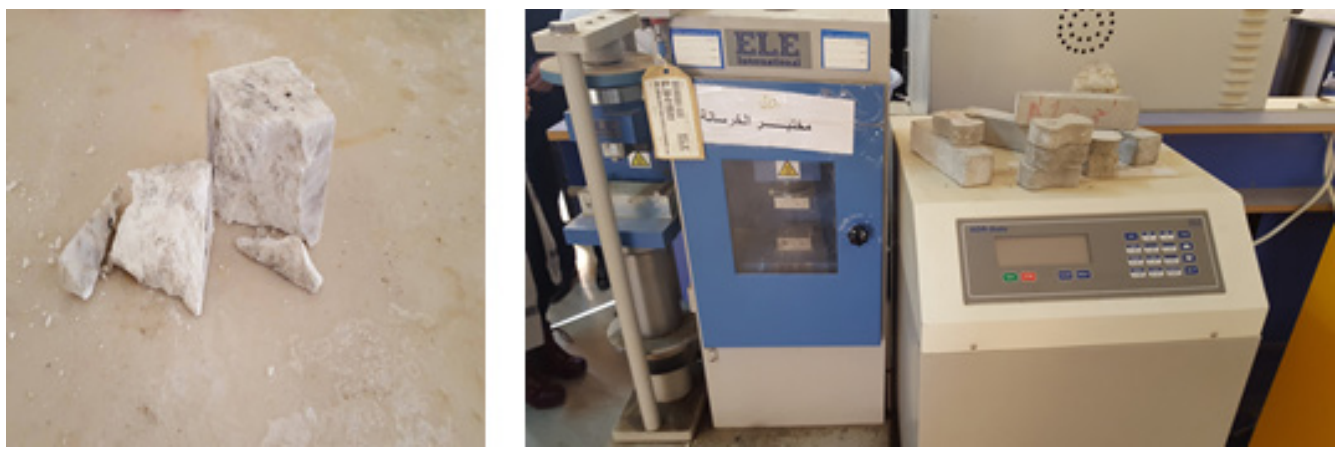

Figure 7. Sample cube assay in compression device and test result 


\subsection{Method}

1. Labourite the model with a light layer of oil for easy opening of the models after the casting process and to reduce the adhesion of the model.

2. Prepare plaster mortar with a standard strength consisting of plaster and water.

3. Fill the mold with a mortar to a depth of $2.5 \mathrm{~cm}$ and mix by moving it several times for the purpose of getting rid of air bubbles and then fill the mold over the edge of the plaster and repeat the previous process.

4. Place the molds in a humid atmosphere of (90-100\%). After hardening the plaster, lift the cubes from the molds and leave them for 24 hours in a humid atmosphere.

5. Store cubes in a standard temperature of $20^{\circ} \mathrm{C}$ and a relative humidity of $65 \%$ for 7 days.

6. Drain the cubes in a well-ventilated oven $\left(40 \pm 2^{\circ}\right)$ (Figure 8).

Calculations: The pressure tolerance of plaster molds is calculated by the following equation:

Calculate the amount of plaster:

Cluster $=$ Density $\times$ Size (3)

Density $=1200\left(\mathrm{~kg} / \mathrm{m}^{3}\right)$
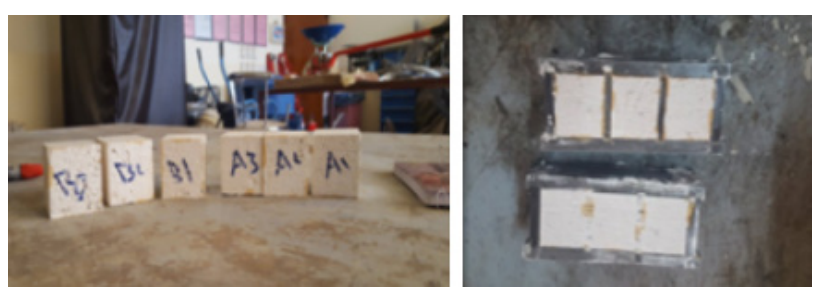

Figure 8. Samples of test cubes for plaster mortar
Size $=5 \times 5 \times 5=750 \mathrm{~cm}^{3}$

Density $=(750 \times 1200 \times 1000) \div 1000000=900 \mathrm{~g}$

Water weight $=0.56 \times 900=504 \mathrm{~g}$

Stress $(\mathrm{Mpa})=($ Pressure load at failure Newton $) /$ (Area exposed to stress $\mathrm{mm}^{2}$ ) (4)

\section{Results}

\subsection{Group I - Chemical analysis of selected samples}

The experimental work on three samples included sample $\mathrm{A}, \mathrm{AD}$ and $\mathrm{AL}$ have been performed. By analyzing the chemical compounds of the samples in private laboratories where the sample analysis was sent to ACMAE ANALYSES laboratory in Canada. The following results were obtained as shown in Table.

Analysis results show convergence samples (AD) and (AL) with the original sample $(A)$ in the chemical characteristics in terms of the percentages of the oxides and their elements.

\subsection{Group II - Physical analysis of selected samples}

This change appears in two main forms: both the stone and the plaster analyses are variables.

9.2.1. The stone test is different in two main ways: the compression of the stone, and the stone absorption

1) Compression test The stone is used to determine the rate of stress by comparing the results of samples (A), $(\mathrm{AL})$ and $(\mathrm{AD})$ selecting the sample with the highest stress to ensure the durability of the building. As shown in Table 2 and Figure 9.

Table 1. Comparison of results of chemical analysis of samples selected between sample A, AL and AD

\begin{tabular}{|c|c|c|c|c|c|c|}
\hline \multicolumn{3}{|c|}{ Unit } & \multirow{2}{*}{$\begin{array}{c}\begin{array}{c}\text { Qishla } \\
\text { sample (A) }\end{array} \\
40.82\end{array}$} & \multirow{2}{*}{$\begin{array}{c}\begin{array}{c}\text { Leylan } \\
\text { Sample }(\mathrm{AL})\end{array} \\
43.48\end{array}$} & \multirow{2}{*}{$\begin{array}{c}\text { Dibis } \\
\text { Sample (AD) }\end{array}$} & \multirow{2}{*}{$\begin{array}{c}\begin{array}{c}\text { Chosen } \\
\text { sample }\end{array} \\
(\mathrm{AD})\end{array}$} \\
\hline Sulfur oxides & $\mathrm{SO} 3$ & $\%$ & & & & \\
\hline Calcium oxide & $\mathrm{CaO}$ & $\%$ & 29.52 & 30.1 & 30.29 & $(\mathrm{AL})$ \\
\hline Aluminum oxide & $\mathrm{Al} 2 \mathrm{O} 3$ & $\%$ & 0.22 & 0.17 & 0.19 & $(\mathrm{AD})$ \\
\hline ferric oxide & $\mathrm{Fe} 2 \mathrm{O} 3$ & $\%$ & 0.16 & 0.12 & 0.1 & $(\mathrm{AL})$ \\
\hline Magnesium oxide & $\mathrm{MgO}$ & $\%$ & 0.44 & 0.37 & 0.42 & $(\mathrm{AD})$ \\
\hline Silicon dioxide & $\mathrm{SiO} 2$ & $\%$ & 1.5 & 0.86 & 1.26 & $(\mathrm{AL})$ \\
\hline Phosphoruspentoxide & $\mathrm{P} 2 \mathrm{O} 5$ & $\%$ & 0.02 & 0.02 & 0.01 & $(\mathrm{AL})$ \\
\hline Sodium oxide & $\mathrm{Na} 2 \mathrm{O}$ & $\%$ & 1.23 & 0.78 & 1.38 & $(\mathrm{AD})$ \\
\hline Potassium oxide & $\mathrm{K} 2 \mathrm{O}$ & $\%$ & 0.06 & 0.05 & 0.07 & $(\mathrm{AL})$ \\
\hline Chloride & $\mathrm{Cl}$ & $\%$ & 2.11 & 1.24 & 2.35 & $(\mathrm{AD})$ \\
\hline Strontium & $\mathrm{Sr}$ & PPM & 3534 & 4561 & 2940 & $(\mathrm{AL})$ \\
\hline Barium & $\mathrm{Ba}$ & PPM & 166 & 121 & 148 & $(\mathrm{AD})$ \\
\hline Nickel & $\mathrm{Ni}$ & PPM & 40 & 41 & 41 & $(\mathrm{AD})$ \\
\hline Rubidium & $\mathrm{Rb}$ & PPM & 11 & 3 & 13 & $(\mathrm{AL})$ \\
\hline Zinc & $\mathrm{Zn}$ & PPM & 13 & 8 & 14 & $(\mathrm{AD})$ \\
\hline Manganese & $\mathrm{Mn}$ & PPM & 100 & 192 & 91 & $(\mathrm{AD})$ \\
\hline Copper & $\mathrm{Cu}$ & PPM & 41 & 36 & 9 & $(\mathrm{AL})$ \\
\hline Ignition & LOI & $\%$ & 23.7 & 22.8 & 22.9 & $(\mathrm{AL})$ \\
\hline
\end{tabular}


From the table above, the sample $(\mathrm{AL})$ strength equals to $(16.13) \mathrm{N} / \mathrm{mm}^{2}$ which is the strongest and closest to the original sample $(\mathrm{A})$ that has a strength of stress rate (21.04) $\mathrm{N} / \mathrm{mm}^{2}$. Thus the sample (AL) is the sample that selected for the restoration of the building of the Qishla regarding the rate of the stress the endurance with higher.

2) The ratio of stone absorption to water: it is used to determine the rate of absorption of stone for each of the samples (A), (AL) and (AD) and to compare the results of

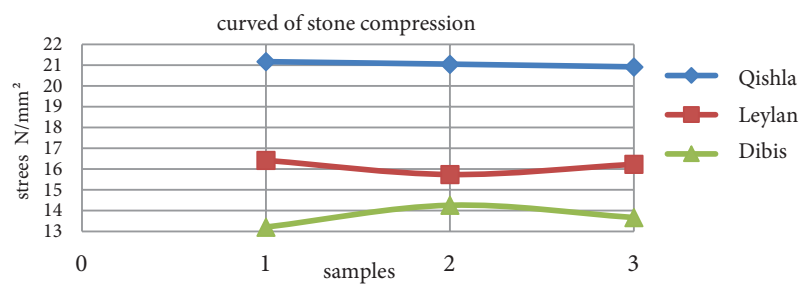

Figure 9. Curved of stone compression

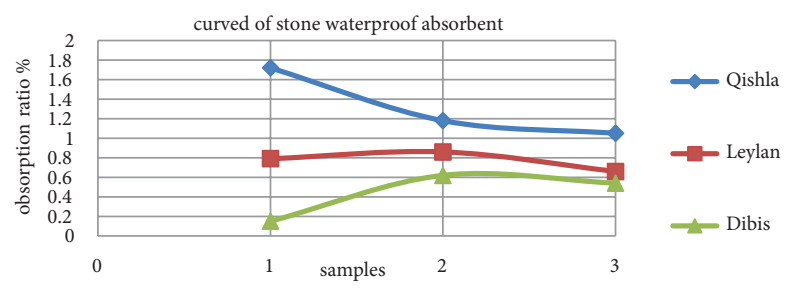

Figure 10. Curved of stone waterproof absorbent the samples and to select the sample with a lower absorption rate to ensure the durability of the building as shown in Table 3 and Figure 10.

Figure 10 appears from the Table above the absorption rate $(\mathrm{AL})$, which is 0.77 , is the closest to the sample absorption rate $(\mathrm{A})$ of the stone, and the bearing of the stone is affected by its absorption of water, as the high absorbance reduces the bearing forces of the stone.

\subsubsection{Compression check of Plaster as shown in Table 4 and Figure 11}

Figure 11 shows that the results of the compressive analyses of plaster mortar were higher than the minimum determined by the Iraqi Standard for the Examination of Squeeze Plaster (IQS 27-1985) where the sample stress rate is equal to $(6.87) \mathrm{N} / \mathrm{mm}^{2}$ and the minimum stress specified by The Iraqi specifications is equal to (3) Newton $/ \mathrm{mm}^{2}$.

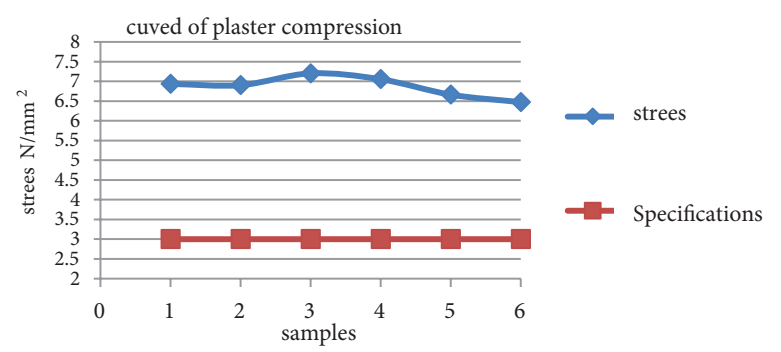

Figure 11. Curved compression plaster

Table 2. Find the stress rate for sample A \& AL \& AD and the percentage of stress for the original sample A

\begin{tabular}{|c|c|c|c|c|c|c|c|c|c|}
\hline Sample & \multicolumn{3}{|c|}{$\mathrm{AD}$} & \multicolumn{3}{|c|}{$\mathrm{AL}$} & \multicolumn{3}{|c|}{ A } \\
\hline form & ad3 & $\mathrm{ad} 2$ & ad1 & al1 & al2 & al1 & a3 & $\mathrm{a} 2$ & a1 \\
\hline Load at Failure (KN) & 32.83 & 32.85 & 33.04 & 39.76 & 37.02 & 41.05 & 50.24 & 49.52 & 51.87 \\
\hline Sample dimension $(\mathrm{cm} \times)$ & $4.9 \star 5$ & $4.8^{\star} 4.9$ & $5 \star 5$ & $5^{\star} 4.9$ & $4.8^{\star} 4.9$ & $5 \star 5$ & $4.9 \star 4.9$ & $4.8^{\star} 4.9$ & $4.9 * 5$ \\
\hline Stress $\left(\mathrm{N} / \mathrm{mm}^{2}\right)$ & 16.23 & 14.26 & 13.21 & 16.23 & 15.74 & 16.42 & 20.92 & 21.05 & 21.17 \\
\hline Rate of stress & \multicolumn{3}{|c|}{13.71} & \multicolumn{3}{|c|}{16.13} & \multicolumn{3}{|c|}{21.04} \\
\hline
\end{tabular}

Table 3. The absorption ratio of sample A \& $\mathrm{AL} \& \mathrm{AD}$ and the percentage of absorption for the original sample $\mathrm{A}$

\begin{tabular}{|l|c|c|c|c|c|c|c|c|c|}
\hline \multicolumn{1}{|c|}{ Sample } & \multicolumn{3}{c|}{ AD } & \multicolumn{3}{c|}{ AL } & \multicolumn{3}{c|}{ A } \\
\hline & $\mathrm{ad} 3$ & $\mathrm{ad} 2$ & $\mathrm{ad} 1$ & $\mathrm{al3}$ & $\mathrm{al} 2$ & $\mathrm{al1}$ & $\mathrm{a} 3$ & $\mathrm{a} 2$ & $\mathrm{a} 1$ \\
\hline Dry weight $(\mathrm{gm})$ & 348.7 & 675.2 & 1183.2 & 925.6 & 651.7 & 731.4 & 1332.4 & 575.8 & 964.4 \\
\hline Wet weight $(\mathrm{gm})$ & 350.6 & 679.4 & 118.5 & 931.8 & 657.3 & 737.2 & 1346.4 & 582.6 & 981 \\
\hline Absorption rate\% & 0.54 & 0.62 & 0.15 & 0.66 & 0.86 & 0.79 & 1.05 & 1.18 & 1.72 \\
\hline Absorption ratio\% & \multicolumn{3}{|c|}{0.44} & & 0.77 & & 1.31 \\
\hline The ratio\% & 33.58 & & & & & \\
\hline
\end{tabular}

Table 4. The results of the plaster compression test consisting of A1, A2, A3, B3, B2, B1

\begin{tabular}{|l|c|c|c|c|c|c|}
\hline \multicolumn{1}{|c|}{ Sample } & B3 & B2 & B1 & A3 & A2 & A1 \\
\hline Pregnancy at Failure $(\mathrm{KN})$ & 16.18 & 16.66 & 17.6 & 18.01 & 17.26 & 17.34 \\
\hline Sample dimension $(\mathrm{cm} \times)$ & $5^{\star} 5$ & $5^{\star} 5$ & $5^{\star} 5$ & $5^{\star} 5$ & $5^{\star} 5$ & $5^{\star} 5$ \\
\hline Stress $\left(\mathrm{N} / \mathrm{mm}^{2}\right)$ & 6.473 & 6.663 & 7.054 & 7.203 & 6.904 & 6.936 \\
\hline Rate & & & & & & 6.87 \\
\hline
\end{tabular}




\section{Conclusions}

- The restoration process in international conventions was related to the principle of compatibility in the form and content of the materials used in the process of reconstruction collapsed parts.

- Restoration operation can be done under the supervision of organizations like the UNSCO or ICOMOS to guarantee keeping cultural heritage buildings on the list of the international cultural heritage buildings.

- Choosing the right restoration materials depends on the chemical and physical tests to determine which sample is the best among the taken samples has the same features or close to the features of the original used materials.

- The result of the chemical analyses showed rapprochement between sample of Dibis stone and samples of Leylan stone in the characteristics of the chemical composition when compared with the original Qishla $s$ stone in terms of the ratios of the oxides and the elements in them. Thus, the physical properties of the selected samples can be used as a determining factor in the determination of the sample used for the restoration of the Qishla s building.

- The stone sample of the LAYLAN quarry is the sample selected for the restoration of the Qishla s building, in terms of the rate of stress and the durability is the highest by $76.66 \%$ compared to the other sample. In addition the absorption rate of the sample of the LAYLAN quarry, which is equal to (0.77) is the closest to the rate of absorption of stone and Qishla s stone bearing is affected by its absorption of water as the high absorption reduces the strength of the stone carrying loads. The results of the compression test for plaster mortar were higher than the minimum determined by the Iraqi Standard for the testing of the thickness of plaster (IQS 27-1985). The sample strength is (6.87) N/mm ${ }^{2}$ and the minimum limit specified by the Iraqi specifications is (3) Newton $/ \mathrm{mm}^{2}$.

\section{References}

Aldhdar, M. (2010). The impact of the wars in the restructuring of the buildings value (Master Thesis). Faculty of Engineering, Cairo University, Giza - Egypt.

ASTM. (2010). C170c170M-15a-standard-testmethod-forcompressive-strength of dimension stone. In Annual Book of ASTM standards (Vol. 04(07), pp. 1-7).

Bassam, M. (2008). The role of reconstruction in the preservation of archaeological buildings historical Sites. Journal of the General Union of Archaeologists, 10(01), 122.

Charola, E. (2016). Stone deterioration characterization for its conservation. Geonomos, 24(2), 16-20.

https://doi.org/10.18285/geonomos.v24i2.836

Feilden, B. (2003). Conservation of historic buildings (3rd ed.). Architectural Press, Amsterdam.

ICOMOS. (2003). ICOMOS charter - principles for the analysis, conserva-tion and structural restoration of architectural heritage. https://www.icomos.org/charters/structures_e.pdf

Iraq, specification. (1984). Compression test of plaster mortar, No. 27.

Lam, F., Lewis, D., \& Sutherland, J. (2008). The Royal Ontario Museum, Toronto. The Arup Journal, 162, 22-33.

Lakhani, R., \& Sharma, R. K. (2018). Strategies for the restoration of heritage buildings: material issues. https://www.researchgate.net/publication/329446459_Strategies_for_the_Restoration_of_Heritage_Buildings_Material_Issues

Mardan, N. (2015, September). The Turkmen Presence in Kirkuk as a model of ethnocentric marriages history and present. Cardinia Magazine, 43(06), 6.

Mibei, G. (2014). Introduction to types and classification of rocks. Presented at Short Course IX on exploration for Geothermal Resources. Organized by UNU-GTP, GDC and KenGen, at Lake Bogoria and Lake Naivasha, Kenya, Nov.

Paajanen, L., \& Muinonen, M. (2013). Use of natural stone and stone construction. The Journal of Saimaa University of Applied Sciences, 322(05), 4-5.

Quist, W. J. (2009). Replacement of natural stone in conservation of historic buildings. Heron, 54(04), 259-267.

Republic of Iraq. (2002). Ministry of State for Tourism and Antiquities Affairs, General Authority for Antiquities and Heritage. Law on the Protection of Antiquities and Heritage, 55.

Saatci, S. (2014). The urban fabric and traditional houses of Kirkuk. Fuzuli prees, Istanbul.

Strenchock, F. (1999). Restoration of heritage structures (Msc Dissertation). Technical University of Catalonia, Spain.

Terzibasi, A. (1988). Old Kerkuku Qishlah. Journal of Kardaslik, 194(64-67)

\section{APPENDIX}

\section{List of abbreviations:}

\begin{tabular}{|ll|ll|l|}
\hline${ }^{*}$ sample of Qishla stone: & A & ${ }^{*}$ sample of Dibis stone: & AD & ${ }^{*}$ samples of Leylan stone: \\
\hline${ }^{*}$ model one of Qishla stone: & a1 & ${ }^{*}$ model one of Dibis stone: & ad1 & ${ }^{*}$ model one of Leylan stone: \\
\hline${ }^{*}$ model two of Qishla stone: & a2 & ${ }^{*}$ model two of Dibis stone: & ad2 & ${ }^{*}$ model two of Leylan stone: \\
\hline${ }^{*}$ model three of Qishla stone: & a3 & ${ }^{*}$ model three of Dibis stone: & ad3 & ${ }^{*}$ model three of Leylan stone: \\
\hline
\end{tabular}

